\title{
Carrier screening for spinal muscular atrophy in Italian population
}

\author{
FRANCESCO CALİ $^{1 *}$, GIUSEPPA RUGGERI ${ }^{1}$, VALERIA CHIAVETTA ${ }^{1}$, CARMELA SCUDERI $^{2}$, SEBASTIANO \\ BIANCA $^{3}$, CHIARA BARONE ${ }^{3}$, ALDA RAGALMUTO ${ }^{1}$, PIETRO SCHINOCCA ${ }^{1}$, GIROLAMO AURELIO VITELLO ${ }^{4}$, \\ VALENTINO ROMANO ${ }^{1,5}$ and SEBASTIANO MUSUMECI ${ }^{4}$ \\ ${ }^{1}$ Laboratorio di Genetica Molecolare, UOC di Genetica Medica, ${ }^{2}$ Unità Operativa di Malattie Neuromuscolari and \\ ${ }^{4}$ Unità Operativa di Neurologia per il Ritardo Mentale, Associazione Oasi Maria SS. (I.R.C.C.S.), 94018 Troina (EN), Italy \\ ${ }^{3}$ Genetica Medica ARNAS Garibaldi Nesima, 95122 Catania, Italy \\ ${ }^{5}$ Dipartimento di Fisica e Chimica, Università degli Studi di Palermo, 90128 Palermo, Italy
}

[Calì F., Ruggeri G., Chiavetta V., Scuderi C., Bianca S., Barone C., Ragalmuto A., Schinocca P., Vitello G. A., Romano V. and Musumeci S. 2014 Carrier screening for spinal muscular atrophy in Italian population. J. Genet. 93, 179-181]

\section{Introduction}

Spinal muscular atrophy (SMA) is an autosomal-recessive neuromuscular disorder characterized by motor neuron degeneration in the anterior horn of the spinal cord and brain stem, resulting in progressive muscle weakness and atrophy. The responsible survival motor neuron gene (SMN1; HGNC: 11117 ) is localized in 5q11.2-13.3. Screening for carriers of SMA is necessary for effective clinical/prenatal diagnosis and genetic counselling. In this study, the copy number of SMN1 gene was determined from a southern Italian population to estimate carrier frequency. This is the first report addressing the estimation of SMA carrier frequency in an Italian population. Our results show that the SMA carrier frequency in Sicily is higher than in the European populations and lower than in Mediterranean/Middle Eastern countries. The carrier testing could be a helpful tool for genetic counselling, to individuals with a positive family history.

SMA is the second most common severe autosomalrecessive disorder after cystic fibrosis and the most frequent genetic cause of infant mortality, with an incidence of one per 6000-10,000 live births (Pearn 1980). Mutations in the survival motor neuron gene (SMN1; HGNC: 11117), localized in 5q11.2-13.3 within a large inverted duplicated element, cause SMA types I, II, III and IV (Lefebvre et al. 1995). Further, between $95 \%$ and $98 \%$ of individuals with recessive SMA have two deletion mutations (deletion of exons 7-8) and the remaining $2-5 \%$ have one deletion mutation (exons 7-8) and a second, different type of mutation (Ogino and Wilson 2002). People generally have between one and three copies of the SMN1 gene. Usually, people with two copies

*For correspondence. E-mail: cali@oasi.en.it. of SMN1, there is one copy of the gene on each chromosome (called ' $1+1$ '). However, it is also possible for a person to have two SMN1 copies arranged together on the same chromosome, and no copies on the other chromosome (called ' $2+0$ '). In this case, the parent is a carrier and is at risk of having a child with SMA if a SMN1 mutation was also passed by the other parent. Dosage analysis cannot predict the difference between ' $1+1$ ' and ' $2+0$ ' arrangements. Both situations are simply detected as having two SMN1 copies.

Identification of SMA carriers has important implications for effective clinical/prenatal diagnosis and genetic counselling; however, in different populations the carrier frequency varies widely between $1 / 20$ and 1/125 (Ogino et al. 2004; Hendrickson et al. 2009; Hasanzad et al. 2010; Sugarman et al. 2012). Caucasians and Ashkenazi Jews have higher carrier rates than Asians, African Americans and Hispanics (Hendrickson et al. 2009). Carrier frequencies in Morocco (1/25) and in Iran and Saudi Arabia (1/20) are higher than in the European populations (from 1/50 to 1/80) (Lyahyai et al. 2012). A population-based study of SMA prevalence in Italy has not yet been conducted, but a frequency of the heterozygote of $1 / 57$ has been inferred in a northeastern Italian (Veneto) population (Mostacciuolo et al. 1992).

The present work was carried out to calculate the carrier frequency of deletion of SMN1 exons 7-8 among the general population of Sicily and to estimate the prevalence of SMA in the study population.

\section{Method}

The project was approved by the local Institution Ethics Committee. Four hundred and fifty unrelated noncon-

Keywords. survival motor neuron gene (SMN1); spinal muscular atrophy; carrier screening; MLPA. 
Table 1. Frequencies, average values RPA ratio, range and standard deviation showed by each probe specific for the MLPA P021 analysis of SMA critical region in the group of 450 normal controls.

\begin{tabular}{|c|c|c|c|c|c|c|}
\hline $\begin{array}{l}\text { SMN1 gene } \\
\text { (HGNC: 11117) }\end{array}$ & Gene copy number & $N=450$ & $\begin{array}{l}\text { Frequency } \\
\quad(\%)\end{array}$ & $\begin{array}{l}\text { Average values } \\
\text { RPA ratio }\end{array}$ & $\begin{array}{l}\text { Minimum/maximum } \\
\text { values RPA ratio }\end{array}$ & SD \\
\hline Exon 7 & 2 copies $(1+1 \text { or } 2+0)^{*}$ & 409 & 90.89 & 1.00 & $0.73-1.25$ & 0.08 \\
\hline Exon 8 & 2 copies $(1+1 \text { or } 2+0)^{*}$ & 409 & 90.89 & 0.99 & $0.67-1.25$ & 0.10 \\
\hline Exon 7 & 1 copy $(1+0)$ & 13 & 2.89 & 0.54 & $0.47-0.64$ & 0.05 \\
\hline Exon 8 & 1 copy $(1+0)$ & 13 & 2.89 & 0.52 & $0.43-0.62$ & 0.06 \\
\hline Exon 7 & 3 copies $(2+1)$ & 28 & 6.22 & 1.49 & $1.32-1.63$ & 0.09 \\
\hline Exon 8 & 3 copies $(2+1)$ & 28 & 6.22 & 1.46 & $1.30-1.62$ & 0.09 \\
\hline
\end{tabular}

*MLPA SMN1 copy number analysis is not able to differentiate the two genotypes.

sanguineous healthy individuals from Sicily (Italy) were selected for this study. Informed consent was obtained from each subject. The multiplex ligation-dependent probe amplification (MLPA) was performed using the SALSA P021 kit, from MRC-Holland (Amsterdam, The Netherlands; www.mrc-holland.com). This kit contains a probe mixture for SMN1 exons 7 and 8 (SMN1; HGNC: 11117), SMN2 exons 7 and 8 (SMN2; HGNC: 11118) and several control fragments located on different chromosomes. All reactions were carried out according to the manufacturer's recommendations (www.mlpa.com). Approximately $200 \mathrm{ng}$ of genomic DNA was used for the MLPA reaction. The MLPA products were analysed using an ABI 3130 Genetic Analyser (Applied Biosystems, Foster City, USA), with GeneScan ROX 500. To process the MLPA deletion/duplication data efficiently, a spreadsheet was generated using Microsoft Excel software. First, the data corresponding to each DNA control sample were normalized by dividing each probe's signal strength (i.e., the area of each peak) by the average signal strength yielded by the 21 control probes to generate for each peak a relative peak area (RPA) value. The RPA value for each probe in the sample was then compared to that of 50 negative samples. The latter ratio was then used to define the following categories: (i) $\sim 1.0$ for the nondeleted/nonduplicated gene region, (ii) $\sim 0.5$ if deleted in heterozygote status, and (iii) $\sim 1.5$ if duplicated. We computed the standard deviation (SD) of the normalized signals of mean RPA ratio relative to each group (1 copy, 2 and 3 copies) (see table 1). MLPA analysis was repeated for samples yielding a SD exceeding the threshold value of 0.1 . Such value approximatively corresponds to the mean value of the standard deviations of the normalized data relative to the probes of all considered individuals. Other details on normalizing and quality test are as described in Calì et al. (2010). All tests that gave a result consistent with one (carrier) or three copies of exons 7-8 of SMN1 gene, were retested using a comparative multiplex dosage analysis (CMDA) protocol as described in Saugier-Veber et al. (2001).

\section{Results and discussion}

The screening results, frequency, mean RPA ratio, range and standard deviation are shown in table 1 . All positive to one (carrier) or three copies of exons 7-8 of SMN1 gene were confirmed using CMDA test (data not shown). Thirteen of the 450 healthy individuals were found to be SMA carriers, with SMN1 exons 7-8 deletion yielding a real carrier prevalence of $1: 34(\sim 3 \%$, table 1$)$. Three copies of $S M N 1$ exons $7-8$ were detected in 28 individuals $(\sim 6 \%$, table 1$)$. However, few of 409/450 individuals (table 1) having two SMN1 exons 7-8 copies may still be deletion carriers $(2+0$ genotype) (see Introduction). This fact highlights the limitation of all quantitative SMN1 analyses that underestimate the SMA carrier rate and has serious genetic counselling implications.

Assuming Hardy-Weinberg equilibrium, this carrier frequency $(1: 34)$ would mean a calculated SMA prevalence of $1 / 4793$. Given that the average number (between years 2002 and 2010) of children born in Sicily is around 50,000 per year (data from ISTAT, http://www.istat.it/), there could be about 10 individuals (each year) with SMN1 homozygous deletion and SMA phenotype, considering no deaths. Our results also show that the carrier frequencies of SMA among Sicilian healthy individuals is higher than in the European populations and lower then in Mediterranean/Middle Eastern countries, probably determined by genetic flows that occurred into the island, due to ancient Mediterranean colonization and to northern African contributions (Di Gaetano et al. 2009). The present study was carried out to estimate the carrier frequency of copy number changes of exons 7-8 of the SMN1 gene among the Sicilian population (Italy) taking in account that the method used could detect approximately 95-98\% of carriers. This is the first report addressing the estimation of SMA carrier frequency in an Italian population, based on a sample of 450 nonrelated healthy individuals. The carrier testing could be a helpful tool for genetic counselling particularly in families with a clear clinical history of SMA. 


\section{Acknowledgement}

This research was supported by the Italian Ministry of Health: Current Research 2012

\section{References}

Calì F., Ruggeri G., Vinci M., Meli C., Carducci C., Leuzzi V. et al. 2010 Exon deletions of the phenylalanine hydroxylase gene in Italian hyperphenylalaninemics. Exp. Mol. Med. 42, 8186.

Di Gaetano C., Cerutti N., Crobu F., Robino C., Inturri S., Gino S. et al. 2009 Differential Greek and northern African migrations to Sicily are supported by genetic evidence from the $\mathrm{Y}$ chromosome. Eur. J. Hum. Genet. 17, 91-99.

Hasanzad M., Azad M., Kahrizi K., Saffar B. S., Nafisi S., Keyhanidoust Z. et al. 2010 Carrier frequency of SMA by quantitative analysis of the SMN1 deletion in the Iranian population. Eur. J. Neurol. 17, 160-162.

Hendrickson B. C., Donohoe C., Akmaev V. R., Sugarman E. A., Labrousse P., Boguslavskiy L. et al. 2009 Differences in SMN1 allele frequencies among ethnic groups within North America. $J$. Med. Genet. 46, 641-644.

Lefebvre S., Bürglen L., Reboullet S., Clermont O., Burlet P., Viollet L. et al. 1995 Identification and characterisation of a spinal muscular atrophy determining gene. Cell 80, 155165.

Lyahyai J., Sbiti A., Barkat A., Ratbi I. and Sefiani A. 2012 Spinal muscular atrophy carrier frequency and estimated prevalence of the disease in Moroccan newborns. Genet. Test. Mol. Biomarkers 16, 215-218.

Mostacciuolo M. L., Danieli G. A., Trevisan C., Müller E. and Angelini C. 1992 Epidemiology of spinal muscular atrophies in a sample of the Italian population. Neuroepidemiology 11, 3438 .

Ogino S. and Wilson R. B. 2002 Genetic testing and risk assessment for spinal muscular atrophy (SMA). Hum. Genet. 111, 477-500.

Ogino S., Wilson R. B. and Gold B. 2004 New insights on the evolution of the SMN1 and SMN2 region: simulation and metaanalysis for allele and haplotype frequency calculations. Eur. J. Hum. Genet. 12, 1015-1023.

Pearn J. 1980 Classification of spinal muscular atrophies. Lancet 1, 919-922.

Saugier-Veber P., Drouot N., Lefebvre S., Charbonnier F., Vial E., Munnich A. and Frébourg T. 2001 Detection of heterozygous SMN1 deletions in SMA families using a simple fluorescent multiplex PCR method. J. Med. Genet. 38, 240-243.

Sugarman E. A., Nagan N., Zhu H., Akmaev V. R., Zhou Z., Rohlfs E. M. et al. 2012 Pan-ethnic carrier screening and prenatal diagnosis for spinal muscular atrophy: clinical laboratory analysis of 472400 specimens. Eur. J. Hum. Genet. 20, 27-32. 
Copyright of Journal of Genetics is the property of Indian Academy of Sciences and its content may not be copied or emailed to multiple sites or posted to a listserv without the copyright holder's express written permission. However, users may print, download, or email articles for individual use. 